\title{
Policy Options to Reduce Fragmentation in the Pooling of Health Insurance Funds in Iran
}

\author{
Mohammad Bazyar ${ }^{1}$, Arash Rashidian ${ }^{1 *}$, Sumit Kane ${ }^{2}$, Mohammad Reza Vaez Mahdavi ${ }^{3}$, Ali Akbari Sari ${ }^{1}$, \\ Leila Doshmangir ${ }^{4}$
}

\begin{abstract}
There are fragmentations in Iran's health insurance system. Multiple health insurance funds exist, without adequate provisions for transfer or redistribution of cross subsidy among them. Multiple risk pools, including several private secondary insurance schemes, have resulted in a tiered health insurance system with inequitable benefit packages for different segments of the population. Also fragmentation might have contributed to inefficiency in the health insurance systems, a low financial protection against healthcare expenditures for the insured persons, high coinsurance rates, a notable rate of insurance coverage duplication, low contribution of well-funded institutes with generous benefit package to the public health insurance schemes, underfunding and severe financial shortages for the public funds, and a lack of transparency and reliable data and statistics for policy-making. We have conducted a policy analysis study, including qualitative interviews of key informants and document analysis. As a result we introduce three policy options: keeping the existing structural fragmentations of social health insurance (SHI) schemes but implementing a comprehensive "policy integration" strategy; consolidation of existing health insurance funds and creating a single national health insurance scheme; and reducing fragmentation by merging minor well-resourced funds together and creating two or three large insurance funds under the umbrella of the existing organizations. These policy options with their advantages and disadvantages are explained in the paper.

Keywords: Fragmentation, Health Insurance Funds in Iran, Integration of Policies, Consolidation, Risk Pooling Copyright: ( 2016 by Kerman University of Medical Sciences

Citation: Bazyar M, Rashidian A, Kane S, Vaez Mahdavi MR, Akbari Sari A, Doshmangir L. Policy options to reduce fragmentation in the pooling of health insurance funds in Iran. Int J Health Policy Manag. 2016;5(4):253-258. doi:10.15171/ijhpm.2016.12
\end{abstract}

Article History:

Received: 12 September 2015 Accepted: 3 February 2016 ePublished: 11 February 2016

\section{Introduction}

Policy Context

Iran has enjoyed a universal coverage of primary healthcare services since 1990s, due to the effective health system structure. ${ }^{1}$ However, chronic maldistribution of secondary care services and hospital beds compounded with financial barriers to such services have been a continuing challenge., As a consequence of the "Universal Health Insurance Act" in 1994, several initiatives have been conducted to increase population coverage and/or financial protection from healthcare costs. ${ }^{4}$ As a result, Iran's population benefits from a high healthcare insurance coverage, estimated at about $83 \%$ of the population in $2010 .{ }^{5}$ It is now believed that over $95 \%$ of the population is under one sort of health insurance coverage as a result of an ambitious health transformation plan starting in 2014.

There are four main public health insurance organizations in the country. The Social Security Organization (SSO); it is one of the largest health insurance organizations which covers all the people employed in the formal private sector and their dependents. The Iran Health Insurance Organization (IHIO); it has four subfunds which provide health insurance for government employees and their dependents, rural residents, the self-employed (Iranians fund) and their dependents, and other sectors (such as students, some professional associations and so on). The Armed Forces Medical Services Insurance Organization, which provides health insurance for military personnel and their families. And finally Imam Khomeini
Relief Foundation Health Insurance, which provides health insurance coverage for the poor, although the population coverage for the latter has reduced to less than $5 \%$ of the population in recent years due to the expanding reach of the IHIO. ${ }^{2,4,6-9}$

There are no transfers or redistribution of cross subsidy between these health insurance schemes with different population risk pools. Cross-subsidization is even limited between the insurance funds managed by IHIO. There are substantial similarities between basic benefit packages for the main social health insurance (SHI) schemes and they have been intended to be virtually the same in terms of service coverage. However, because the basic benefit package was not comprehensive enough, and the financial and organizational autonomy of the insurers, each health insurance organization has tried to raise additional resources to extend the basic benefit package for their beneficiaries and in practice there are differences between their packages.

In addition to these main insurers, there are about 17 smaller 'institutional' health insurance funds such as those offered by some banks, the Tehran Municipality, the National Broadcasting Organization, private insurance companies, the Petroleum Industry Health Organization which have launched health insurance coverage for their own employees and dependents outside of the main health insurance organizations. ${ }^{6,710}$ These institutions are generally small in population size and, compared to the population coverage, enjoy abundant financial resources. In this paper, these 17 
funds are called minor well-resourced funds. The existence of multiple risk pools in health insurance system of Iran has led to a tiered health insurance system with inequitable benefit packages for different segments of the population. The depth of benefits packages and also health services covered by health insurance schemes are different for each scheme. ${ }^{6-8}$ Thus the Iranian health insurance system can be considered as a fragmented insurance system.

Fragmentation in the Pooling of Health Insurance Funds in Iran: A Main Challenge

As each scheme covers a specific population group because of incremental expansion of health insurance coverage over the time, population within each health insurance scheme tend to be different from those in other schemes in terms of various features including socio-economic status, risk of illness, and demographic features. Consequently risks have been distributed unevenly among risk pools, limiting redistribution of risks and cross-subsidization across the pools. ${ }^{6,11}$

Inefficiency in health insurance system, high out-of-pocket (OOP) expenditures, fee-for-service (FFS) payments to hospitals and physicians, a low financial protection against health services for the insured persons, considerable coinsurance rates, low contribution of well-funded institutes with generous benefit package to the public health insurance schemes, underfunding and severe financial shortages for the public funds, and a lack of transparency and not reliable data and statistics for health insurance policy-making, are some of insurance system problems that can be attributed to the fragmentation in health insurance funds directly or indirectly. ${ }^{2,6,8,12}$ Iran's constitution (Article 2) emphasizes the importance of securing equity and justice among people in general and Article 29 explicitly notes the provision of access to healthcare and insurance as a universal right of the public. The fourth and fifth Economic, Social and Cultural Development Plans of Iran have obliged the government to ensure equity in health by providing the same basic benefit package for all Iranians. ${ }^{10,13}$

In countries like Iran with formal, obligatory, and large health insurance schemes, reducing fragmentation in health insurance funds, and consolidation of multiple health insurance schemes is considered a desirable option to improve health insurance system performance. ${ }^{14}$ Some countries such as Turkey, ${ }^{15-17}$ South Korea, ${ }^{18,19}$ Brazil, Thailand, Ghana, Peru, ${ }^{20}$ Estonia, Lithuania, ${ }^{21}$ and Indonesia ${ }^{22-24}$ have adopted this policy to expand the size of the risk pool, and to improve the equity, efficiency, and redistribution of cross-subsidization throughout the entire health insurance system. ${ }^{14,20}$

\section{Methods}

This paper is part of a larger "analysis for policy" study of merging SHI funds in Iran. A purposeful sample of key informants with substantial managerial and policy experiences, or extensive education and research related to health systems and health insurance were selected for interviews.

To gather sufficient information to cover all aspects of the merging health insurance schemes, we tried to identify all the relevant stakeholders as much as possible. Various stakeholders including the Ministry of Health and Medical Education (MoHME), the Ministry of Cooperatives, Labor and Social Welfare, the Vise-Presidency for Strategic Planning and Supervision, the four main public health insurance organizations, the Parliament of the Islamic Republic of Iran (Majlis), Other health insurance organizations like Petroleum Industry Health Organization, banks, Tehran Municipality, the High Council of Health Insurance, healthcare providers and facilities were identified. Sixty-seven face to face interviews were conducted and transcribed. Transcribed interviews were analyzed by using a thematic analysis approach following the framework methodology that employed the use of MAXQDA10 software. ${ }^{25}$ Relevant documents were reviewed to complete data collection as well. The policy options and their pros and cons were adopted from interviews and document analysis.

Policy Options to Tackle the Problem of Fragmentation in Health Insurance System

Table 1 provides a summary of the policy situation analysis based on the interviews and document reviews context. The policy options have been provided in the context of Iran's health insurance system. Advantages and disadvantages of these three policy options are summarized in Table 2.

\section{Option 1: Keeping the Existing Structural Fragmentations of Social Health Insurance Schemes but Implementing a Comprehensive "Policy Integration" Strategy}

Fragmented health insurance system in Iran is mainly a result of incremental extension of insurance coverage for different parts of population over the time. The literature has noted that once separate insurance schemes are formed, it is very politically difficult to merge these multiple insurance schemes together. ${ }^{20}$ Hence it is advisable to move towards integration of 'policies' rather than structural integration of SHI funds. This policy option is called "virtual integration." One good example of this kind of integration can be integration of insurance contribution rates. An important improvement was made in this direction a few years ago, and premium rate for governmental employees changed from a fixed rate for every insured individual towards a proportional deduction of payroll. It was a great step but there are still some challenges, for example the ceilings on insurance contribution rate varies among the SHI funds. For those insured by the SSO, their contribution increases depending on their earning level until their earning reaches 7 -fold of the minimum wage. Earnings above this ceiling do not result in further contributions. In contrast, for those civil servants insured by the IHIO, the maximum contribution level is reached when their earning is only 2 -fold of the minimum wage. Effort should be made towards filling this gap and this policy must be extended to other groups with fixed contribution rates as much as possible. Policy integration can be applied to other aspects of the insurance policies. For example, health insurance organizations should follow the same preset principles for contracting providers. Also common processes and regulations can be applied for the review and reimbursement of medical claims. This can reduce the complexity of regulations and standards that providers have to consider for each insurance organization and can facilitate the relationship between healthcare providers and SHI organizations. Also this policy can lead to lowering of the administrative costs. Such "policy integration" could also include the creation of a single comprehensive databank for all groups of population and sharing registration data of 


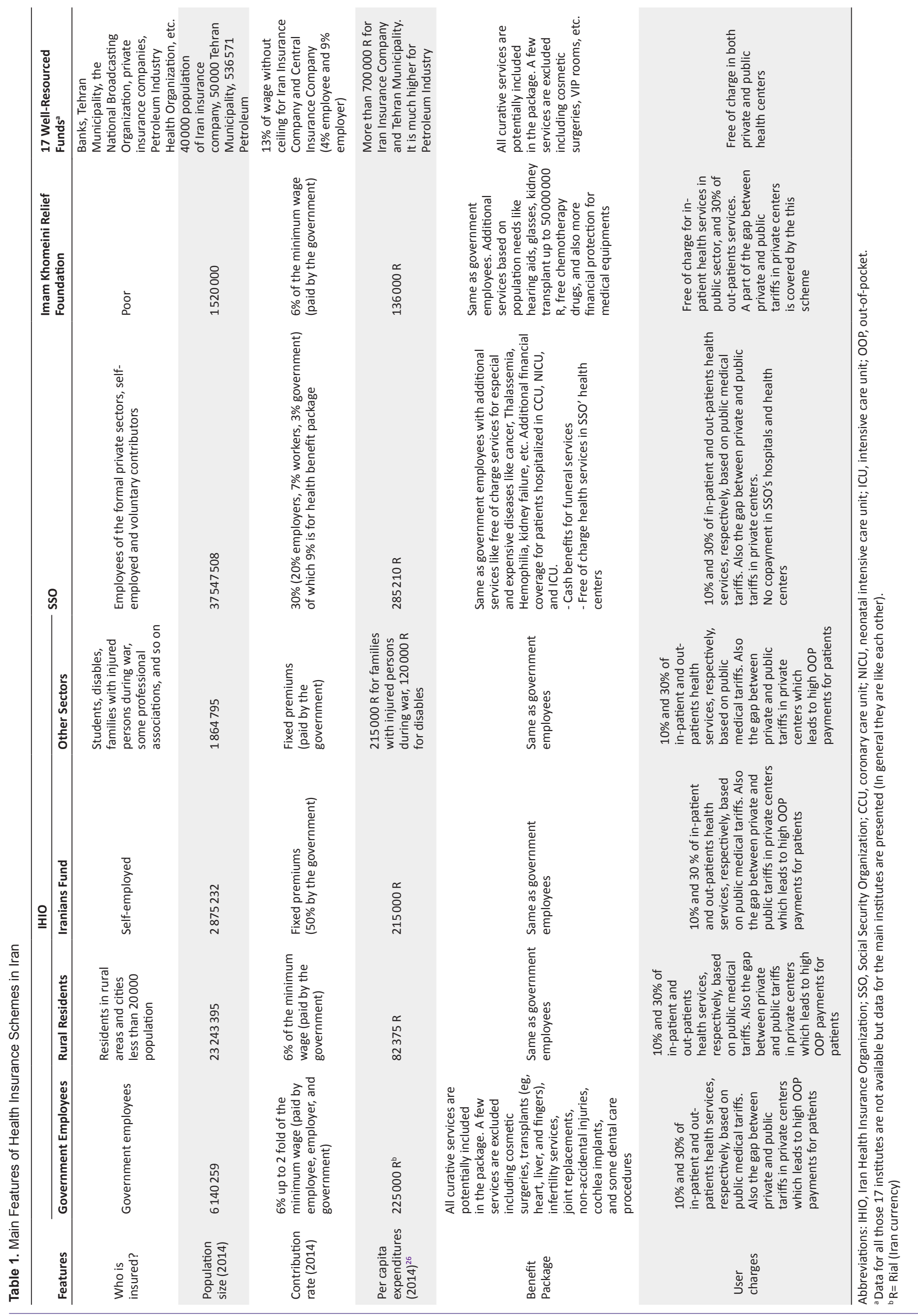




\begin{tabular}{|c|c|c|c|}
\hline Policy Option & $\begin{array}{l}\text { Keeping the existing structural fragmentations of } \\
\text { SHI schemes but implementing a comprehensive } \\
\text { "policy integration" strategy }\end{array}$ & $\begin{array}{l}\text { Consolidation of the existing health } \\
\text { insurance funds and creating a single } \\
\text { national health insurance scheme }\end{array}$ & $\begin{array}{l}\text { Reducing fragmentation by merging minor } \\
\text { well-resourced funds together and creating } 2-3 \\
\text { large insurance funds under the umbrella of } \\
\text { the existing organizations }\end{array}$ \\
\hline Advantages & $\begin{array}{l}\text { - Less resistance from existing health insurance } \\
\text { schemes } \\
\text { Previous experience in some areas in Iran } \\
\text { - Supporting harmonization and coordination } \\
\text { in non-controversial areas and avoiding } \\
\text { touching contentious areas like financial } \\
\text { autonomy } \\
\text { Accepting the autonomy of health insurance } \\
\text { organizations and not touching their physical } \\
\text { structures } \\
\text { Acceptable for health insurance organizations } \\
\text { Removing the differences in working } \\
\text { activities and executive policies among health } \\
\text { insurance schemes }\end{array}$ & $\begin{array}{l}\text { Improving risk pooling and cross- } \\
\text { subsidization among population } \\
\text { Improving equity in access to } \\
\text { healthcare services among } \\
\text { population } \\
\text { Opening a new policy window for } \\
\text { further improvements in health } \\
\text { insurance system and can contribute } \\
\text { to better achievement of other } \\
\text { relevant reforms in health system } \\
\text { International experiences from other } \\
\text { countries about consolidation to } \\
\text { learn from } \\
\text { Strengthening strategic purchasing }\end{array}$ & $\begin{array}{l}\text { Reducing fragmentation in risk pools to } \\
\text { great extend (but not complete) } \\
\text { Less political resistance from small } \\
\text { better-off insurance organizations } \\
\text { because of being governmental } \\
\text { Improving risk pooling among small } \\
\text { better-off schemes } \\
\text { Operating as a pilot plan to learn from it } \\
\text { to create a single scheme in the future if } \\
\text { necessary } \\
\text { Strengthening strategic purchasing }\end{array}$ \\
\hline Disadvantages & $\begin{array}{l}\text { Would not improve the redistribution of } \\
\text { risk and cross-subsidization between health } \\
\text { insurance funds } \\
\text { High potentiality for fragmentation of policies } \\
\text { again over the time }\end{array}$ & $\begin{array}{l}\text { A tough political decision with } \\
\text { political resistance because of } \\
\text { structural and financial integration } \\
\text { Facing a lot of operational challenges } \\
\text { in different aspects of health } \\
\text { insurance such as benefit package, } \\
\text { financial mechanisms, organizational } \\
\text { structure, operational processes, and } \\
\text { engagement with providers } \\
\text { Requiring a comprehensive plan for } \\
\text { implementation which is difficult in } \\
\text { developing countries }\end{array}$ & $\begin{array}{l}\text { - Not improving risk pooling and equity in } \\
\text { the whole health insurance system }\end{array}$ \\
\hline
\end{tabular}

beneficiaries to prevent duplication of insurance coverage among SHI schemes-some people have access to two or more different insurance policies which is a big challenge now-can be considered as a by-product of this policy option. There have been important improvements in this regard in the last year (2014) between the SSO and the IHIO, which should be expanded to all health insurance schemes. One another important area that must be integrated is the benefit package. Currently the SHI schemes are different in terms of the range of health services they cover, and more importantly the depth of coverage and amount of financial protection that they provide for their beneficiaries. The advantage of this policy option is to support harmonization and coordination in non-controversial areas (ie, the benefit packages) and avoiding integration of other contentious areas like organizational structures. Since this policy accepts the autonomy of SHI schemes, therefore, SHI organizations will be more receptive to such a policy. But this policy option would not improve one main function of health insurance, which is risk pooling. Currently because of fragmentation there is no redistribution of risk and crosssubsidization between health insurance funds. The option of "policy integration" would not address this problem.

There is also a long history of attempts to achieve 'policy integration.' Despite the establishment of the High Council of Health Insurance in 1994 as a policy-making body for regulating the health insurance schemes, ${ }^{4,8,27}$ implementation of the so called "integration of policies" has been difficult. Because of financial and organizational autonomy of SHI schemes, health insurance organizations tend to act differently. As a result despite defining the same basic benefit package in the High Council of Health Insurance for SHI schemes at least twice over the past decade, still there are differences in their benefit packages. There is a potential that further attempts to harmonize benefit packages will have a similar outcome. For this reason some interviewees believe that "... According to the history of Iranian health insurance system and the past experience, we could not execute 'policy integration' effectively while keeping fragmentation ... the last resort for solving health insurance fragmentation and its problems is merging all existing health insurance schemes with each other and creating a single one..." (Senior health insurance expert).

\section{Option 2: Consolidation of the Existing Health Insurance Funds and Creating a Single National Health Insurance Scheme}

This option involves the merging all existing health insurance funds together and establishment of a single national fund with the same benefit package for all Iranian citizens. This policy includes a structural integration of insurance organizations.

Selection of this policy can be seen as a major reform for health insurance system and the health system as a whole. Major reforms by virtue are more difficult to implement. ${ }^{28}$ But successful implementation of this policy option can solve most of the problems attributed to fragmentation within health insurance system mentioned above. For example, this policy would improve risk pooling and cross-subsidization among SHI schemes and in turn would provide more financial protection for the poor. By providing the same basic benefit package for all, this policy would reduce inequality among different segments of population in access to health services. Also this policy can open a new policy window for further improvements in health insurance system and can contribute to better achievement of other relevant reforms in health system.

From the feasibility perspective, this kind of merging would be a tough political decision. A great deal of resistance from all health insurance organizations and other relevant stakeholders 
and also political challenges should be expected. Feasibility of merging in following dimensions including economical, political, technical and managerial, socio-cultural, and legislative must be considered carefully.

In Iran some main public SHI schemes (ie, IHIO, Armed Forces Medical Insurance, and Imam Khomeini Relief Foundation) are governmental and rely substantially on government budget for funding. They are struggling with chronic inadequate financial resources. ${ }^{12,29} \mathrm{~A}$ considerable share of population works in informal economy with no regular wage, and continuous support from public budget will be needed. ${ }^{6,8}$ Also an important issue in health financing system in Iran over the last decade has been high out of pocket healthcare expenditures (around 54\% of total health expenditures), which can refer to not effective health insurance system as one of the possible reasons. ${ }^{10,12,13,30}$ Considering these problems, planning to merge the existing health insurance schemes and creating a single national one needs at least a great financial consideration. Given that the country have faced a lot of economical sanctions, and a negative economic growth over the recent years, some policy opponents argue that the conditions for merging are not ready and it might be better to postpone implementation of this policy to a later stage, until we experience a reliable economic growth.

Political feasibility is also very vital for doing this policy. There are different actors with political power against merging in Iran. Political will to implement this policy is very important. One of the senior health insurance experts said: "no excuse is acceptable now, we have law for consolidation of SHI schemes, documents support this policy, and experts understand the importance of this policy. We don't have only political will. We need only political will to consolidate them together, that's it." Implementation of this policy would require to deal with many operational challenges in different aspects of health insurance organization such as benefit package, financing mechanisms, organizational structure, operational processes, and engagement with providers for purchasing health services. ${ }^{11}$ These challenges must be identified and the best solutions must be found to solve them.

Option 3: Reducing Fragmentation by Merging Minor WellResourced Funds Together and Creating 2-3 Large Insurance Funds Under the Umbrella of the Existing Organizations

There are multiple health insurance funds in Iran with different coverage of population size ranging from less than 50 thousands to about 37 million people that exacerbates fragmentation in the overall risk pool. As discussed in the introduction, apart from the four main public health insurance organizations, there are about 17 more minor funds which have launched health insurance coverage for their own employees individually. Enjoying abundant financial resources, these minor funds provide generous health benefit packages for their beneficiaries, while some of the public health insurance organizations that rely mainly on government budget for funding suffer from budget constraints. Inequality between these small funds and large public schemes like SSO and IHIO is more severe and because of fragmentation in the risk pools, these well-resourced minor funds have no contribution to the public health schemes and have weakened social solidarity across the health insurance system. ${ }^{6,710}$
Although these funds are small in terms of population size, given the resources they have at their disposal, they may have significant impact on health system and would have a great influence on health market prices and expenditures. Furthermore, many of these smaller, well-resourced funds are not working under the High Council of Health Insurance policies; this makes the health insurance system chaotic. For example they purchase health services from private providers at higher prices in comparison to the larger and less-resourced public SHI organizations. These differences undermine the power of all purchasers to negotiate and implement strategic purchasing and supervise the healthcare providers. Also it is worth to mention that because many of these organizations provide health insurance as a "fringe benefit" and they do not have a separate structure for health insurance like other public health insurance organizations, ${ }^{6}$ pooling their funds is structurally less difficult. So merging these small funds with each other under the umbrella of main SHI systems can reduce fragmentation in health insurance system to a great extent. In this way, there will be fewer health insurance funds with more balanced population sizes. Also 'policy integration' should be applied for all the scheme in addition. That means policy option 3 in effect should be implemented alongside option 1 . This can be a good start to reduce fragmentation within health insurance system and can be considered as a springboard to draw lessons from it for understanding advantages, disadvantages and challenges of merging. These lessons can be used for merging the main public health insurance organizations in the future when conditions are ripe and if it would become feasible to do so.

\section{Conclusions and Recommendations}

Three possible options were introduced for reducing fragmentation in health insurance system in Iran. Even though we explained them independently, they are to a large extent interrelated; they can be considered as prerequisites for each other. For example both "integration of policies" and "merging of better-off minor funds together" can be the initial step to move toward complete merging of all insurance funds and creating a single scheme. ${ }^{3}$ When most procedures and processes become integrated, thinking about structural merging would not be that much difficult and there would be much less operational challenges for complete consolidation. Creating a single national insurance is best considered a long-term policy goal; and it is better to start with reducing fragmentation and work towards merging of minor well-resourced funds. Even it can be extended to other public governmental schemes. It means that apart from SSO (as a non-governmental organization with strong political opposition against consolidation) by merging all minor wellresourced funds and governmental SHI schemes including IHIO and Imam-Khomeini Relief Foundation to each other, one governmental scheme can be created alongside SSO. This integration may or may not involve the Armed Forces Medical Insurance scheme. ${ }^{15,16,31}$ Creating two (or three) large health insurance organizations with a full risk pooling within each scheme, and developing an effective oversight framework can address most of problems originating from fragmentation. It is worth highlighting that even though consolidation of health insurance funds is a necessary step for the development 
of an equitable and efficient health system, it is not enough by itself. To be useful, it should be accompanied by contributing reforms in supply side like improving provision of healthcare in rural areas and smaller towns, expanding the family physician system to urban areas, improving the referral system, furthering the use of evidence-based clinical guidelines, moving away from FFS provider payment approaches, and controlling overall healthcare expenditures. ${ }^{1,4}$

Creating a single national scheme in Iran is an attractive choice and international literature supports it. ${ }^{32,33}$ The policy options provided here, in effect provide the main policy routes towards health insurance integration, while highlighting the benefits and potential challenges of each option.

Ethical issues

Not applicable.

\section{Competing interests}

The authors declare that they have no competing interests.

\section{Authors' contributions}

Study topic (AR and MB); Study methodology (AR, MB, MRVM, and AAS); Conducting interviews (MB); Data analysis (AR, MB, MRVM, and AAS); Drafting and developing of manuscript (All authors).

\section{Authors' affiliations}

${ }^{1}$ Department of Health Management and Economics, School of Public Health, Tehran University of Medical Sciences, Tehran, Iran. ${ }^{2}$ Department of Development Policy and Practice, Royal Tropical Institute, Amsterdam, The Netherlands. ${ }^{3}$ Department of Physiology, School of Medicine, Shahed University, Tehran, Iran. ${ }^{4}$ Department of Health Services Management, School of Management and Medical Informatics, Iranian Center of Excellence in Health Management, Tabriz University of Medical Sciences, Tabriz, Iran.

\section{References}

1. Takian A, Rashidian A, Kabir MJ. Expediency and coincidence in re-engineering a health system: an interpretive approach to formation of family medicine in Iran. Health Policy Plan. 2011;26(2):163-173. doi:10.1093/heapol/czq036

2. Kavosi Z, Rashidian A, Pourreza A, et al. Inequality in household catastrophic health care expenditure in a low-income society of Iran. Health Policy Plan. 2012;27(7):613-623. doi:10.1093/heapol/ czs001

3. Doshmangir L, Rashidian A, Ravaghi H, Takian A, Jafari M. The experience of implementing the board of trustees' policy in teaching hospitals in Iran: an example of health system decentralization. Int J Health Policy Manag. 2015;4(4):207-214. doi:10.15171/ ijhpm.2014.115

4. Doshmangir L, Rashidian A, Jafari M, Takian A, Ravaghi H. Opening the black box: the experiences and lessons from the public hospitals autonomy policy in Iran. Arch Iran Med. 2015;18(7):416-424.

5. Rashidian A, Khosravi A, Khabiri R, et al. Islamic Republic of Iran's Multiple Indicator Demograpphic and Healh Survey (IrMIDHS) 2010. Tehran: Ministry of Health and Medical Education; 2012.

6. Iran health in fifth Economic, Social and Cultural Development Plan (Persian). Tehran; 2009.

7. Jadidfard MP, Yazdani S, Khoshnevisan MH. Social insurance for dental care in Iran: a developing scheme for a developing country. Oral Health Dent Manag. 2012;11:189-198.

8. Ibrahimipour $\mathrm{H}$, Maleki M-R, Brown R, Gohari M, Karimi I, Dehnavieh R. A qualitative study of the difficulties in reaching sustainable universal health insurance coverage in Iran. Health Policy Planning. 2011;26(6):485-495. doi:10.1093/heapol/czq084

9. Karasawa $Y$, Hozumi $Y$, Imamura S, Kuroyanagi T. JMAPresident's Speech. JMA. 2009;52(1):121.

10. The regulations of fifth Economic, Social and Cultural Development Plan. Tehran: Iranian Parliament; 2011.

11. Wang H, Switlick K, Ortiz C, Zurita B, Connor C. Health Insurance
Handbook: How to Make It Work. World Bank Publications; 2012.

12. Davari M, HaycoxA, Walley $T$. The Iranian health insurance system; past experiences, present challenges and future strategies. Iran $J$ Public Health. 2012;41(9):1-9.

13. The regulations of fourth Economic, Social and Cultural Development Plan. Tehran: Iranian Parliament; 2004.

14. Bärnighausen $T$, Sauerborn $R$. One hundred and eighteen years of the German health insurance system: are there any lessons for middle-and low-income countries? Soc Sci Med. 2002;54(10):1559-1587. doi:10.1016/s0277-9536(01)00137-x

15. Atun R, Aydın S, Chakraborty $S$, et al. Universal health coverage in Turkey: enhancement of equity. Lancet. 2013;382(9886):65-99. doi:10.1016/s0140-6736(13)61051-x

16. Yardim MS, Cilingiroglu N, Yardim N. Financial protection in health in Turkey: the effects of the Health Transformation Programme. Health Policy Plan 2014;29(2):177-192. doi:10.1093/heapol/ czt002

17. Yıldırım HH, Yıldırım T. Healthcare financing reform in Turkey: context and salient features. Journal of European Social Policy. 2011;21(2):178-193. doi:10.1177/0958928710395045

18. Kwon S. Healthcare financing reform and the new single payer system in the Republic of Korea: Social solidarity or efficiency? Int Soc Secur Rev. 2003;56(1):75-94. doi:10.1111/1468-246x.00150

19. Kwon S. Thirty years of national health insurance in South Korea: lessons for achieving universal health care coverage. Health Policy Plan. 2009;24(1):63-71. doi:10.1093/heapol/czn037

20. Maeda A, Araujo E, Cashin C, Harris J, Ikegami N, Reich MR. Universal health coverage for inclusive and sustainable development: a synthesis of 11 country case studies. World Bank Publications; 2014.

21. Thomson S, Foubister T, Mossialos E. Financing health care in the European Union Challenges and policy responses. Copenhagen: WHO, EMPL; 2009.

22. Lagomarsino G, Garabrant A, Adyas A, Muga R, Otoo N. Moving towards universal health coverage: health insurance reforms in nine developing countries in Africa and Asia. Lancet. 2012;380(9845):933-943. doi:10.1016/s0140-6736(12)61147-7

23. Thabrany $\mathrm{H}$. Politics of National Health Insurance of Indonesia: A New Era of Universal Coverage. Paper presented at: The 7th European Conference on Health Economics; Center for Health Economic and Policy Studies, University of Indonesia; 2008.

24. Thabrany $\mathrm{H}$. Social health insurance in Indonesia: current status and the proposed national health insurance. Paper presented at: Social Health Insurance Workshop by WHO SEARO; March 1315, 2003.

25. Rashidian A, Eccles MP, Russell I. Falling on stony ground? A qualitative study of implementation of clinical guidelines' prescribing recommendations in primary care. Health Policy. 2008;85(2):148-161. doi:10.1016/j.healthpol.2007.07.011

26. Hajimahmoodi H. Common basic health benefit package for all Iranians: a solution to implement health system macro-policies. Tehran: Iran Health Insurance Organization; 2014.

27. Takian A, Rashidian A, Doshmangir L. The experience of purchaser-provider split in the implementation of family physician and rural health insurance in Iran: an institutional approach. Health Policy Plan. 2015;1:11. doi:10.1093/heapol/czu135

28. Wilsford D. Path dependency, or why history makes it difficult but not impossible to reform health care systems in a big way. J Public Policy. 1994;14(3):251-283. doi:10.1017/s0143814x00007285

29. Marnani AB, Teymourzadeh E, Bahadori M, Ravangard R, Pour JS. Challenges of a large health insurance organization in Iran: A Qualitative Study. International Journal of Collaborative Research on Internal Medicine \& Public Health. 2012;4:1050-1062.

30. National Health Accounts Islamic Republic of Iran, 2008.

31. Schäfer $W$, Kroneman $M$, Boerma $W$, et al. The Netherlands: health system review. Health Syst Transit. 2010;12(1):v-xxvii.

32. Carrin $G$, James $C$. Reaching universal coverage via social health insurance: key design features in the transition period. Geneva: WHO; 2004.

33. Smith PC, Witter SN. Risk pooling in health care financing: the implications for health system performance. Washington, DC: World Bank; 2004. 